\title{
Mechanisms of Brain Injury in Bacterial Meningitis: Workshop Summary
}

\author{
Hans-Walter Pfister, Adriano Fontana, \\ Martin G. Täuber, Alexander Tomasz, \\ and W. Michael Scheld
}

\author{
From the Departmont of Netrology: Klinikwn Groshadern. Ludnig- \\ Maximilians Univesin). Munich. Gormany: the Deparment of Clinirat \\ Immumologl: Universitatsspital. Zurich. Swit-ertand: the Microbial \\ Pathogenesis Unit. San Francisco General Hospital. San Francisco. \\ California, USA: the Laboratory of Microbiology. The Rockefelles

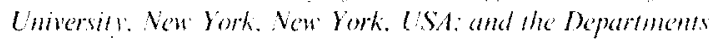

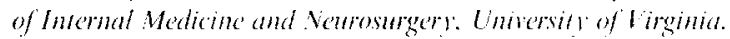 \\ Chatontesille. Virginia. LSA
}

\begin{abstract}
Morbidity and mortality associated with bacterial meningitis remain high, although antibiotic therapy has improved during recent decades. The major intracranial complications of bacterial meningitis are cerebrovascular arterial and venous involvement, brain edema, and hydrocephalus with a subsequent increase of intracranial pressure. Experiments in animal models and cell culture systems have focused on the pathogenesis and pathophysiology of bacterial meningitis in an attempt to identify the bacterial and/or host factors responsible for brain injury during the course of infection. An international workshop entitled "Bacterial Meningitis: Mechanisms of Brain Injury" was organized by the Department of Neurology at the University of Munich and was held in Eibsee, Germany, in June 1993. This conference provided a forum for the exchange of current information on bacterial meningitis, including data on the clinical spectrum of complications, the associated morphological alterations, the role of soluble inflammatory mediators (in particular cytokines) and of leukocyte-endothelial cell interactions in tissue injury, and the molecular mechanisms of neuronal injury, with potential mediators such as reactive oxygen species, reactive nitrogen species, and excitatory amino acids. It is hoped that a better understanding of the pathophysiological events that take place during bacterial meningitis will lead to the develop ment of new therapeutic regimens.
\end{abstract}

Although the recent licensure of Hacmophilus influenzae type $b$ (Hib) polysaccharide conjugate protein vaccines has had a marked impact on the incidence of invasive Hib disease in the United States and Western Europe, bacterial meningitis overall remains a significant problem worldwide. In addition, despite the introduction of new antimicrobial agents and improved diagnostic techniques. the mortality and morbidity associated with bacterial meningitis remain unacceptably high. This discrepancy between a rapid bacteriologic response at the site of infection (i.e., eradication of viable bacteria from the CSF due to treatment with potent bactericidal agents) and the persistence of the associated neurological sequelae and mortality has prompted intense investigation over the past two decades into the pathophysiology

Received 13 December 1993; revised 4 March 1994.

The workshop summarized herein was held in Eibsee, Germany, on 25 and 26 June 1993

Reprints or correspondence: Dr. Hans-Walter Pfister. Klinikum Grosshadern, Ludwig-Maximilians University. Marchioninistrasse 15.81336 Munich, Germany.

Clinical Infectious Diseases 1994;19:463-79

(c) 1994 hy The University of Chicago. All rights rescrved.

$1058-4838 / 94 / 1903-0010 \$ 02.00$ of this disease. Indeed, recent clinical studies have employed adjunctive agents (e.g. dexamethasone) in an attempt to reduce mortality and alleviate neurological sequelac $[1-4]$. These studies and the resulting recommendations regarding the use of adjunctive dexamethasone have recently been reviewed $[5,6]$.

In line with the current emphasis on the pathogenesis and pathophysiology of bacterial meningitis. two workshops were held in California in the 1980s [7]. Recognizing that many advances have been made in this field in the several years since those meetings, the Department of Neurology at the University of Munich organized a similar workshop, which was held in Eibsee, Germany. on 25 and 26 June 1993. As is evident from its title- "Bacterial Meningitis: Mechanisms of Brain Injury" - the workshop focused on the pathophysiology of brain dysfunction during bacterial meningitis. Also considered, however, were many other areas of investigation. including pathogenesis, diagnosis, and therapy. The workshop brought together approximately 50 scientists working in diverse ficlds (including neurology, infectious diseases, pediatrics, neuropathology, microbiology. immunology, molecular biology, and free-radical chemistry) in a retting favorable to the exchange of ideas. This article summarizes the presentations delivered at the workshop and, in light of these 
presentations, suggests some fruitful areas for future investigation.

\section{Clinical Aspects of Brain Injury in Bacterial Meningitis}

Karen Roos (Indianapolis, Indiana, USA) presented a broad overview of the clinical aspects of bacterial meningitis, especially its complications. Roos reviewed a retrospective study documenting various complications of community-acquired meningitis in adults [8]. On admission or within the first 24 hours thereafter, $29 \%$ of patients had focal seizures or focal neurological findings. Previous studies had shown that seizures occurring during acute meningitis correlate with subsequent (late) seizures and with neurological sequelae. Sixty percent of the seizures associated with the acute disease occur in the first 2 days of hospitalization, and $20 \%-40 \%$ of all patients with bacterial meningitis develop seizures at some point. Focal and generalized seizures as well as unprovoked seizures are documented in $\sim 13 \%$ of survivors within 5 years after the acute illness. The pathophysiological picture of seizures in meningitis is complex and includes fever, hyponatremia (due to the inappropriate secretion of antidiuretic hormone), cerebrovascular disease (focal ischemia and/or infarction), intracranial mass lesions (brain abscess, subdural effusion, or subdural empyema), and antibiotic toxicity [9].

Roos's presentation and the subsequent discussion underscored some practical issues in the management of seizures. One recommendation is to treat all patients who have pneumococcal meningitis with phenytoin at the time of presentation (loading dose, $20 \mathrm{mg} / \mathrm{kg}$ iv) in light of the high incidence of seizure activity in this group. Such treatment may prevent the development of status epilepticus but apparently does not reduce the incidence of focal seizures. The impact of this practice on ultimate mortality is unknown. Roos also discussed the pathophysiology and management of increased intracranial pressure (ICP). The development of increasing ICP is suggested by findings on clinical examination. A patient who is awake and alert does not need an ICP-monitoring device: however, as the level of consciousness deteriorates from confusion to stupor and then to coma, such a device should be used. Components in the management of increased ICP include (1) hyperventilation (to lower arterial carbon dioxide pressure $\left[\mathrm{PaCO}_{2}\right]$ to $25 \mathrm{~mm} \mathrm{Hg}$ ), (2) elevation of the head of the bed to 30 degrees, and (3) induction of coma with use of pentobarbital (loading dose, $5-10 \mathrm{mg} / \mathrm{kg}$. with the serum level titrated to achieve a burst-suppression pattern on electroencephalography). No consensus was reached by the participants on the use of mannitol in the routine management of bacterial meningitis. Roos recommended the use of dexamethasone $(0.15 \mathrm{mg} / \mathrm{kg}$ iv $)$ every 6 hours for the first 4 days of antimicrobial therapy, with the first dose of dexamethasone administered 20 minutes before the first dose of antibiotic.

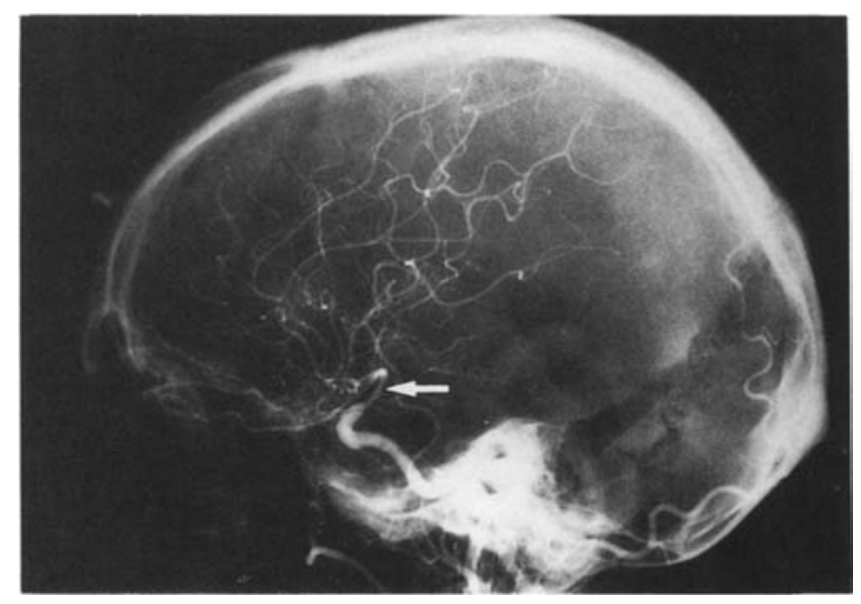

Figure 1. Right-carotid angiography (lateral view from a common internal carotid artery injection) in a 66-year-old patient with pneumococcal meningitis. Angiography disclosed marked narrowing in the supraclinoid portion of the right internal carotid artery (arrow); this change resembled vasospasm associated with subarachnoid hemorrhage secondary to aneurysm rupture.

The results of a prospective study of 86 adult patients with bacterial meningitis were reviewed by Hans-Walter Pfister (Munich, Germany) [10]. This was the first published prospective study of neurological complications in such patients. All patients with a Glasgow coma scale score of $<8$, with focal deficits, or with no improvement after 3 days of antibiotic therapy underwent computed tomography (CT). If the coma score was still $<8$ after 3 more days of therapy, patients underwent angiography as well. Of the 86 patients, 35 suffered in tracranial complications, including angiographically documented cerebrovascular involvement in 13 cases, cerebral edema in 12, hydrocephalus in 10, and cerebral herniation in 7 . Some patients had obvious narrowing of the major arteries at the base of the brain-a finding that is suggestive of vasospasm (figure 1) and is analogous to the situation observed in some cases of subarachnoid hemorrhage. Cerebrovascular complications were associated with a very poor prognosis: 6 patients died, 5 developed neurological sequelae, and only 2 recovered completely. Hydrocephalus was documented as early as the first day after admission and up to several weeks after the initiation of therapy. The systemic complications during the acute illness consisted mainly of septic shock, disseminated intravascular coagulation, and the adult respiratory distress syndrome.

Frank Erbguth (Erlangen, Germany) stressed that patients with bacterial meningitis may have focal signs and symptoms or seizures that mask the underlying diffuse process. The differential diagnosis includes arterial lesions (involving small, medium, and/or major arterial branches), venous occlusion, and cerebritis. Hypodense lesions evident on CT may not appear for several days after admission. Erbguth reminded participants that patients may develop a strokelike syndrome in the absence of fever. 
Volker Schuchardt (Heidelberg. Germany) presented the results of a long-term follow-up study of 73 patients with bacterial meningitis, including 10 patients with tuberculous meningitis. A poor prognosis was associated with the extremes of age, severe underlying diseases, a pneumococcal or tuberculous etiology, the presence of cerebritis or abscess (as detected by (T), and coma. This series from Heidelberg was consistent with other large series of adult patients with bacterial meningitis in terms of the incidence of sequelac and/or complications [11, 12].

Benjamin C. P. Lee (St. Louis. Missouri, USA) discussed the intriguing use of magnetic resonance imaging (MRI) and magnetic resonance (MR) angiography in the diagnosis of complications of bacterial meningitis. MRI and MR angiography are very sensitive for the detection of venous and arterial changes, including infarction, venous sinus thrombosis. and arterial stenosis, occlusion, and spasm. MR angiography, which does not require contrast enhancement, is clearly superior to CT for the diagnosis of thrombosis of cavernous and other major dural sinuses and may be a suitable alternative to conventional angiography. However. MR angiography is dependent on the rate of blood flow and cannot differentiate slow flow from total occlusion. Because it yields images of the internal auditory canal and the cochlear aqueduct, MRI may prove useful for differentiating the routes of infection leading to hearing impairment during bacterial meningitis

Finally, Hilmar Prange (Göttingen, Germany) discussed the CSF concentration of the elastase- $\alpha-1$ proteinase inhibitor as a marker for discriminating bacterial from viral meningitis. He described studies in which the concentration of this inhibitor was elevated in CSF from 20 patients with bacterial meningitis and from a few patients with tuberculous meningitis but not in CSF from patien ts with viral meningitis or other neurological diseases, including Lyme neuroborreliosis. Concentrations in patients with bacterial meningitis and those in patients with viral meningitis did not overlap. Thus, measurement of this inhibitor may be useful in differentiating these diseases. Follow-up evaluation of the patients suggested that the CSF concentration of this inhibitor correlates with CSF neutrophil concentration.

\section{Morphological Alterations During Bacterial Meningitis}

Philip R. Dodge (St. Louis) began the session with a complete review of the route of infection, pathogenesis, pathology, and complications of bacterial meningitis. The focus of the presentation was that-as cited in several reviews and in an editorial published several years ago by Morton N. Swart7. in the Nen' England Journal of Medicine- "meningitis involves more than just the meninges" $[13,14]$.

Cerebrovascular involvement is a frequent complication of bacterial meningitis [15]. In addition to infiltration of the vessel wall by inflammatory cells, an active vascular re- sponse to the infection-i.e.. vdsospasm-may occur. As a consequence of vascular involvement, brain infarction may take place [16]: in rare cases, spinal cord infarction has been reported. Subdural effusion is not a common problem in the adult population but in some studies has occurred in $30^{\text {r }}$ $50 \%$ of children with bacterial meningitis. Only $\sim 1 \%$ of children with subdural fluid collections develop subdural empyema, which usually requires surgical intervention. The cerebral ventricles frequently become enlarged. However. in only $1 \%-2 \%$ of patients is hydrocephalus severe enough 10 require surgical treatment. The most common neurological complication in children is some degree of sensorineural hearing impairment. A prospective study of acute bacterial meningitis in children showed that $\sim 10 \%$ of patients had persistent bilateral or unilateral sensorineural hearing loss [17]. This impairment is most likely secondary to cochlear dysfunction due to the presence of viable bacteria in the circhlea and cochlear aqueduct. Infarction due to local bloodvessel invasion may also be an important factor.

The neuropathology of experimental pneumococcal meningitis in an adult rat model was discussed by Martin (;. Täuber (San Francisco). With his colleagues, Täuber cxamined neuropathological features between 24 hours and 5 days after infection. Early changes appeared to be confined to the subarachnoid space (SAS); later in the infection, granulocytic infiltrates were found along cortical vessels in the Virchow-Robin spaces. Some of these infiltrates appeared to be evolving into frank abscesses. Although studies of the rat model documented extensive leukocytic infiltration along blood vessels into the cortical parenchyma. they revealed little neuronal damage adjacent to the infiltrates. The extent of SAS inflammation and vascular involvement appeared to increase with the size of the bacterial inoculum in this model. The background neuropil was altered focally. and few pyknotic neurons were seen. Neuronal changes were detected in only a minority of animals. Some changes were found in the hippocampus. The paucity of findings indicative of neuronal injury and the focal nature of the changes that were detected were prominent points in Täuber's presentation. During the discussion, the lack of induction of heat-shock protein 72 was mentioned [18]; in light of this observation. it is doubtful that all of the changes documented were secondary to hypoxia alone. Furthermore, since there was virtually no change in the CSF glucose concentration, the changes were not due solely to hypoglycemia and/or hypoglycorrhachia. The correlation of neuronal changes with the bacterial concentration in CSF and with the CSF leukocyte response, the improved resolution with electron microscopy. and the use of other bacterial pathogens (e.g., gram-negative organisms) for challenge were cited as promising areas for future investigation.

The toxic effects of pneumococci on cultured rat astrocytes and cerebral endothelial cells were reviewed by Andrea Bernatowicz (Munich). Pneumococcal cytotoxicity was as- 

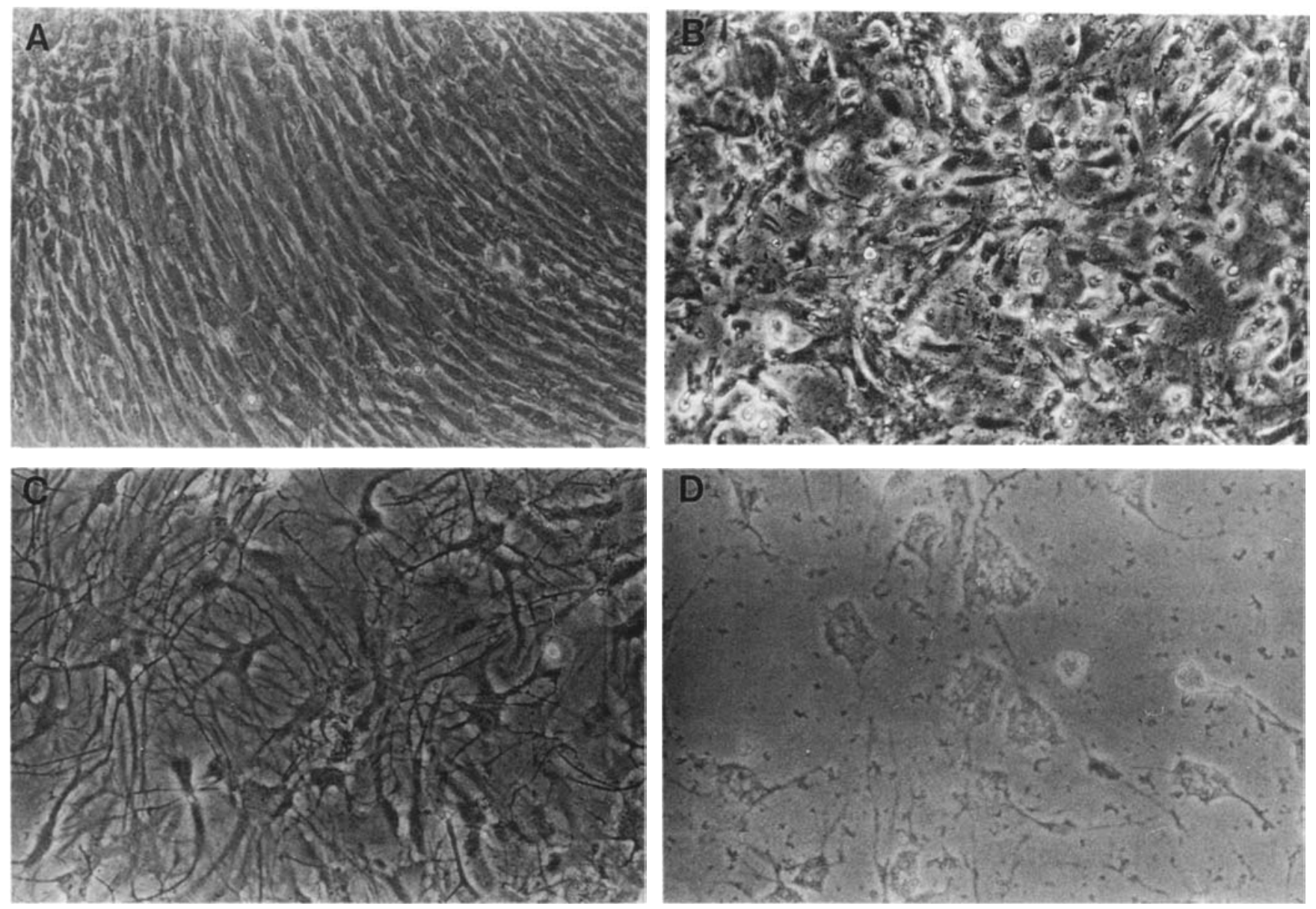

Figure 2. Cytotoxicity of live pneumococci for cultured rat cerebral endothelial cells and astrocytes. $A$ : Confluent monolayer of primary rat endothelial cells cultured for 5 days. $B$ : Endothelial cells 6 hours after exposure to live pneumococci $\left(10^{7} \mathrm{cfu} / \mathrm{mL}\right)$. The monolayer is destroyed. Lysed cells can be identified. Some islands of endothelial cells are still recognizable. $C$ : Primary rat astrocytes cultured for 14 days. $D$ : Astrocytes 48 hours after exposure to live pneumococci $\left(10^{7} \mathrm{cfu} / \mathrm{mL}\right)$. The polynuclear symplasms are disconnected, and the cell contours can no longer be recognized.

sessed by morphological studies and measurements of lactate dehydrogenase (LDH) activity. Primary cultures of unpassaged astrocytes and of endothelial cells up to the first passage were used. Damage to astrocytes was documented morphologically after exposure to heat-inactivated pneumococci. LDH activity was apparent as early as 0.5 hour after exposure of astrocytes to pneumococci. In contrast, neither morphological alterations nor LDH activity was apparent in endothelial cells after exposure to heat-inactivated pneumococci for 0.5 hour to 192 hours. However, morphological changes in endothelial cells were seen after exposure to live pneumococci (figure 2). The pneumococcal strain used in such studies appears to be critical. The investigators used the $\mathrm{S} 3$ strain, which is noninflammatory in a rabbit model when heat inactivated, presumably because the capsule prevents recognition of the proinflammatory cell wall. It was suggested that the heat-inactivated, unencapsulated R6 strain be used in this assay.
Finally, Pedro M. Faustmann (Essen, Germany) presented some preliminary data documenting the early appearance of mononuclear phagocytes in the SAS during acute meningitis. Specifically, these cells appeared in the SAS of both rabbits and rats within 1 hour of the intracerebral injection of complement component $\mathrm{C} 5 \mathrm{a}$ ( $100 \mu \mathrm{g}$ in rabbits and $10 \mu \mathrm{g}$ in rats). Electron microscopy revealed interaction of the macrophages with polymorphonuclear leukocytes (PMNs) via pseudopodia in the cisterns of the SAS. In addition, an interaction of macrophages and astroglia was detected. Studies with monoclonal antibodies specific for mononuclear cells and/or for cells of macrophage lineage showed an increased number of ED2-positive cells within the SAS in the first hour after stimulation in rats. This very early phase of experimental meningitis was the focus of some discussion, which centered in particular on the specificity of the antibody (ED2) and the source of the mononuclear cells. Mononuclear cells or macrophages may be mobilized from 
sites within the CNS or may enter the SAS from an intravascular source. These possibilities require further experimental assessment.

\section{How Microorganisms Challenge the Host in Bacterial Meningitis}

Alexander Tomasz (New York, New York, USA) began his review by reminding workshop participants of the rapid spread and increasing incidence of pneumococci resistant to multiple antibiotics. He cited a case in the United States in which ceftriaxone treatment of pneumococcal meningitis failed. The isolate was resistant to penicillin, third-generation cephalosporins, imipenem, erythromycin, chloramphenicol, tetracycline, and trimethoprim-sulfamethoxazole. Ultimately, vancomycin had to be used in this instance.

There are $\sim 500,000$ cases of pneumococcal pneumonia and 5,000 cases of meningitis annually in the United States, and the fatality rate for meningitis is still around $25 \%-30 \%$. A recent report from South Africa described pneumococcal meningitis in children; mortality due to penicillin-resistant pneumococci was nearly $50 \%$ higher than that due to penicillin-susceptible strains [19]. The high incidence of resistant pneumococcal strains in several countries and the need for bactericidal activity to control pneumococcal meningitis constitute a major challenge for the designers of new antimicrobial agents.

Experiments in a rabbit model indicate that CSF offers a poor environment for the multiplication of at least some pneumococcal strains. In some instances a net increase in bacterial titer was preceded by lag times as long as $20-30$ hours after the intracerebral inoculation of an inoculum of $10^{3}-10^{4} \mathrm{cfu}$. Once bacterial growth commences, the time of onset of CSF leukocytosis is a remarkably sensitive indicator of the bacterial concentration. In studies with several capsular type 2, type 3, and type 19 strains of pneumococci, the number of PMNs in the CSF began to rise sharply as the bacterial concentration reached a threshold range (a few times $10^{6} \mathrm{cfu}$ ).

Whether or not iv injection of a bolus of ampicillin causes an inflammatory overload (known as the antibiotic-induced inflammatory burst) also depends on and is very sensitive to the concentration of bacteria in the CSF at the time of the injection. Ampicillin had no impact on the course of rapid pleocytosis when the bacterial concentration was already above the threshold range. The antibiotic's injection shortly before this threshold concentration was reached resulted in the inflammatory burst, while its injection several hours earlier actually postponed the onset of inflammation.

The nature of the inflammatory agent(s) released spontaneously at the inflammatory threshold bacterial concentration or during treatment with ampicillin is not clear. The ultimate wall-degradation products of pneumococcal autoly- tic amidase (the enzyme responsible for the disintegration of pneumococci during ampicillin-induced lysis) have only poor or moderate inflammatory activity. On the other hand. the in vivo triggering of this enzyme shortly after treatment of the bacteria with ampicillin causes a release in to the medium of highly polymerized cell-wall structures containing an intact network of peptidoglycan and teichoic acid in a soluble form [20]. The specific inflammatory activity of this macromolecule remains to be tested. An additional intracellular inflammatory agent that does not behave like cell walls has been identified.

Biochemical studies on the specific inflammatory activity of well-defined cell-wall fractions from pneumococci and staphylococci have continued. Structural variants of staphylococcal and pneumococcal muropeptides [2 1] differ greatly in inflammatory potential. For instance, oligomeric muropeptides from the staphylococcal peptidoglycan exhibit much less inflammatory activity than monomeric subcomponents. Whole cell walls from a penicillin-susceptible pneumococcal strain and its penicillin-resistant transformants show different degrees of inflammatory activity, with the resistant organism's wall causing more rapid inflammation. This difference is reproduced when muropeptides of $<1,000$ daltons from the two bacteria are compared. These observations suggest the existence of one or more muropeptide receptors on a host cell in the CSF space.

Introduction of cell-wall components or live pneumococci into the cisterna magna triggers an enormous number of molecular and pathophysiological events. Collaborative experiments involving Tomasz's and Pfister's groups have identified one of the early events as an increasc in regional cerebral blood flow. which is followed by an increase in ICP and pleocytosis. Studies with combinations of well-defined bacterial inflammatory components and a variety of anti-inflammatory agents (e.g., dexamethasone, superoxide dismutase. transforming growth factor $\beta$. antibody to (D)/8. and $\mathrm{cy}$ clooxygenase inhibitors) may enable us to organize these events into a definitive inflammatory pathway.

Arnold L. Smith (Seattle. Washington. USA) next discussed the mechanisms of nasopharyngeal colonization by Hib. Smith reviewed the results obtained in the infant macaque model of Hib meningitis [22]. The first histopathologic lesion in the CNS in this model is choroid plexitis. This finding suggests that Hib enters the (NS through the choroid plexus. As in the rabbit model of pneumococcal meningitis. no SAS inflammation develops until bacterial concentrations in CSF reach $\sim 10^{6} \mathrm{cfu} / \mathrm{ml}$. The use of the primate model is appropriate since Hib is specific for adhesion to primate epithelium. Smith reviewed the role of fimbriae in this adhesion. The expression of fimbriae may be switched on or off according to the conditions in which Hib is growing (for example, on HeLa cells or in broth). In cell lines that mimic the nasopharyngeal epithelium. the bacteria can 
"sense where it is," and fimbrial expression may be switched on. Furthermore, Hib is capable of accurately regulating fimbrial phase variation in vivo. For example, $\alpha$-fimbriae are expressed to enhance binding to the anterior nasopharynx and $\beta$-fimbriae to facilitate binding to posterior ciliated nasopharyngeal cells. Smith's presentation and the discussion that followed underscored the need for appropriate in vitro and in vivo systems in which to evaluate the pathogenesis and pathophysiology of meningeal pathogens, many of which are adapted only to primates. In vivo models are critical for the delineation of complex pathophysiological and microbiological events. The differences between models may be subtle, and the interpretation of results obtained in rodent models may be problematic in some respects.

In the next presentation, Barbara Spellerberg (New York) discussed preliminary results of studies of the isolation of a receptor for pneumococci on human brain endothelial cells. Previous experiments had suggested that the pneumococcal cell wall plays a role in the attachment of Streptococcus pneumoniae to human umbilical-vein endothelial cells [23]. In the studies described by Spellerberg, brain endothelial-cell lysates were probed by western blots with antibodies specific for the pneumococcal cell wall, and one band was detected. Brain endothelial cells were then used to develop a cDNA library with $\lambda$-GTll phage and expression in Escherichia coli. A plaque assay with ${ }^{35} \mathrm{~S}$-labeled pneumococci was used to identify putative receptors for the pneumococcal cell wall on brain endothelial cells. A $116-\mathrm{kD}$ fusion protein of two clones was identified as a potential receptor. The discussion focused on the specificity of those findings. The specificity of the receptor for brain endothelial cells and for organisms other than pneumococci is unknown. No direct evidence that the receptor is surface-expressed on endothelium was presented. These exciting preliminary data suggested a variety of areas for productive investigation in the future.

A second presentation by Martin $G$. Täuber focused on the question: Are bacterial products neurotoxic? Primary neuronal cultures from embryonic rat brain consist of $90 \%-$ 95\% pure neurons, with some contamination by astrocytes and glial cells. For standard assays of neurotoxicity, primary neurons are grown in culture for $\sim 12$ days and are then exposed to bacteria and/or bacterial products for 2 days. Täuber presented evidence that primary neurons are less sensitive to heat-killed pneumococci (R6 strain) than are U 373 astrocytes in tissue culture. Similarly, primary neurons are less sensitive to pneumococcal cell-wall components than are U373 cells, which are destroyed in a dose-dependent manner. No change in toxicity in neurons was noted after exposure to lipoteichoic acid or lipopolysaccharide (LPS) from Neisseria meningitidis at concentrations up to 25 $\mu \mathrm{g} / \mathrm{mL}$. U373 cells also exhibited minimal evidence of toxicity in the MTT assay after exposure to LPS. The striking resistance of these neuronal cells to various bacterial products was the subject of further discussion.

Finally, Hans Lassmann (Vienna, Austria) described experiments in a rat model of experimental autoimmune encephalomyelitis (EAE) $[24,25]$ combining immunocytochemical techniques, ultrastructural studies, and in situ nick translation. Lassmann and co-workers found that up to $49 \%$ of $\mathrm{T}$ lymphocytes in EAE lesions showed signs of apoptosis (programmed cell death) when recovered during disease. Thus apoptosis of $T$ lymphocytes is one possible mechanism for the elimination of these cells from inflammatory brain lesions. These intriguing results may or may not be relevant to bacterial meningitis.

\section{Soluble Inflammatory Mediators}

Various aspects of the role of cytokines and soluble mediators in the development of brain injury during bacterial meningitis were considered. Bernhard Moser (Berne, Switzerland) reviewed the functional and molecular characteristics of interleukin $8(\mathrm{IL}-8)$, related cytokines, and their receptors. IL-8 was discovered about 6 years ago to be a chemotactic cytokine in vitro. Injection of IL-8 into the skin of rats induced a rather pronounced local inflammatory responseconsisting mainly of PMNs - within 4 hours after challenge. The inflammatory potency of IL-8 after intradermal injection was confirmed by studies of rabbits and humans. IL-8, formerly referred to as neutrophil-activating peptide 1 (NAP1), belongs to the family of chcmokines (chemotactic cytokines; for a review, see [26]). On the basis of the arrangement of the first two cysteines, the chemokines are divided into two subfamilies. In the CXC chemokines, the first two cysteines $(\mathrm{Cs})$ are separated by one amino acid $(\mathrm{X})$; this group includes IL-8. the GRO (growth-related gene) peptides, and NAP-2. In the CC chemokines, the two first cysteines are adjacent. The most prominent members of this group are monocyte-chemotaclic proteins 1,2 , and 3 and macrophageinflammatory proteins $I \alpha$ and $1 \beta$. The CXC chemokines appear to be highly selective for polymorphonuclear phagocytes, whereas the CC chemokines specifically activate mononuclear cells, including monocytes, eosinophils, basophils, and lymphocytes.

IL-8 is produced by various leukocytes and by a large number of tissue cells upon stimulation with LPS or the proinflammatory cylokines IL-I and tumor necrosis factor (TNF). IL-8, which is strongly chemotactic for PMNs, causes modifications in the shape of neutrophils, release of enzymes, stimulation of the respiratory burst, and upregulation of $\beta$-integrins CD-11/CD-18. IL-8 binds to at least two different PMN receptors, $\mathrm{p} 44$ and $\mathrm{p} 70$. The first receptor is more specific for IL-8 than for related cytokines, while the latter has a similar affinity for IL-8, GRO- $\alpha$, and NAP-2. The two IL-8 receptors have a seven-transmembrane domain architecture 
typical of $G$ protein-coupled receptors. The major form of IL-8 isolated from the medium of cultures of activated blood monocytes consists of 72 amino acids and has been identified as a dimer by nuclear MR studies and X-ray diffraction of IL-8 crystals. The C terminus of the molecule is not involved directly in receptor binding, but deletions at the $\mathrm{N}$ terminus reduce the activity of IL- 8 . The integrity of each of the three residues that precede the first cysteine $\left(\mathrm{Glu}^{4}-\mathrm{Leu}^{5}\right.$ $\left.\mathrm{Arg}^{6} ; \mathrm{ELR}\right)$ is critical for receptor binding and neutrophil-stimulating activity. Recently, a series of analogues of IL-8 (472)-the truncated form of IL-8 with the N-terminal sequence ELRC - were synthesized as potential IL- 8 antagonists [27]. The discussion of this elegant work focused on the potential role of IL-8 in CNS disease. LPS induces the expression of IL-8, but the role of this cytokine in CNS infection is unknown. The time course of IL-8 expression after LPS stimulation requires further study. Whether or not IL-8 receptors exist on endothelial cells also needs to be determined.

The potential role of IL- 8 in experimental meningitis was investigated by Rachel Dumont and Terry O'Reilly (Basel, Switzerland). The authors noted that IL- 8 was present in the CSF of patients with bacterial meningitis at concentrations ranging from 0.3 to $24 \mathrm{ng} / \mathrm{mL}$. IL-8 is capable of enhancing PMN migration across an endothelial-cell monolayer and therefore may play a role in SAS inflammation. These researchers injected IL- 8 and related substances (human recombinant IL-8, rabbit IL-8, human recombinant GRO, and human recombinant NAP-2) intracisternally into rabbits. The results. somewhat surprisingly, documented a lack of CSF pleocytosis during the 7 hours after challenge with all four molecules. However, the rabbits did respond to intracisternal challenge with LPS injected 7 hours after IL-8. The discussion of this presentation emphasized future experiments on topics such as the injection of IL-8 along with other cytokines, the injection of monoclonal antibodies to IL-8 along with an LPS challenge, and the potential influence of IL-8 on blood-brain barrier distuption.

The role of soluble inflammatory mediators in the pathophysiology of bacterial meningitis was reviewed by Karl Frei (Zurich, Switzerland). In collaboration with Adriano Fontana, Frei asked whether cytokines produced intrathecally in the CNS during experimental infection were involved in the elimination of microbes from the CNS. In a mouse model of Listeria monocytogenes meningitis, these investigators documented that TNF and IL- 6 were present in the CSF at 4 hours and that concentrations peaked at $\sim 24$ hours after intracerebral inoculation of $L$. monocytogenes. In contrast, interferon $\gamma$ (IFN- $\gamma$ ) was not detectable until 24 hours after challenge. Perhaps the most significant finding was that IL10 was also produced late (up to 72 hours) in the course of listeriosis in mice [28]. The authors used an in vitro system of murine macrophages (J77A-1 cells) on coverslips to investi- gate the effect of pretreatment with various cytokines on listerial infection in vitro. No increase in listericidal activity was apparent after pretreatment with TNF or IL-6. However. a marked increase in the listericidal activity of J774A-I cells was evident after preexposure to IFN- $\gamma$ (i.e., activated macrophages) and this increase was dependent on the production of nitric oxide. An interesting finding was that $1 \mathrm{~L}-10 \mathrm{im}-$ paired the listericidal activity of macrophages-an effect duplicated when macrophages were exposed to CSF drawn from mice 48 hours after infection. This effect was reversed by preexposure to a monoclonal antibody to IL-10, which inhibits nitric oxide synthase. Although IFN- $\gamma$ and IL-I0 may not play a similar role in meningitis because of the presence of extracellular bacteria, the potential role of cytokine modulation of the late events in infection and the complex interplay of the various cytokines are topics of interest. IL-10 is produced mainly by $\mathrm{TH} 2$ cells, including monocytes and macrophages. During the discussion period. Frei presented data documenting elevated concentrations of IL-10 in $95 \%$ of CSF samples from children with bacterial meningitis but in only $3 \%$ of samples from children with viral meningitis. IL-10 concentrations ranged from $\sim 100$ to well over 20,000 $\mathrm{pg} / \mathrm{mL}$. The potential role of $\mathrm{IL}-10$ in the diagnosis of meningitis and its potential anticytokine activity late in the disease clearly require further investigation.

Jay H. Tureen (San Francisco) discussed the effects of TNF on cerebral blood flow and metabolism. With his associates, Tureen challenged rabbits intracisternally with type III pneumococci at two concentrations $\left(5 \times 10^{6} \mathrm{cfu}\right.$ and $5 \times$ $10^{4} \mathrm{cfu}$ ) and measured cerebral blood flow (radiolabeled microsphere technique), rate of cerebral oxygen metabolism. CSF lactate level, CSF TNF level (L929 cytotoxicity assay). and CSF bacterial titers 16 hours and 20 hours later. Ceftriaxone therapy was initiated 16 hours after challenge. Increased bacterial concentrations in CSF correlated with increased concentrations of lactate and TNF. CSF lactate concentrations were further increased after treatment with ceftriaxone, which also elicited a burst of TNF activity. Perhaps most important, TNF concer trations in CSF correlated inversely with cerebral blood flow and cerebral oxygen uptake. These findings may reflect the increased incidence of neurological sequelae among patients with high CSF bacterial densities associated with a shift to anaerobic metabolism. In discussing this presentation, participants attempted to define the primary event in these pathophysiologic alterations. It was suggested that the primary event was a decrease in brain oxygen demand coupled with a reduction in cerebral blood flow. The driving force is clearly a critical variable. Studies to measure critical variables after challenge with TNF and/or monoclonal antibody to TNF are planned.

The effect of inflammatory products on primary neurons in tissue culture was discussed by Martin G. Täuber (San Francisco). Previous experiments had suggested that the mu- 
rine neuronal cell line HN 33.1 was sensitive to various cytokines, in particular TNF [29]. These studies indicated that the cytotoxicity in CSF from animals with bacterial meningitis was attributable to TNF since soluble TNF receptors blocked virtually all of this activity except that observed late after challenge with either live pneumococci or pneumococcal cell wall. Twelve-day-old primary neuronal cultures were exposed over 2 days to various cytokines, and cytotoxicity was measured with the MTT (3-[4,5-dimethylthiazol-2-yl]2.5-diphenyltetrazolium bromide) assay. Although cytotoxicity was observed after exposure to CSF samples from animals with pneumococcal meningitis diluted in culture medium to $20 \%-30 \%$ ( $\mathrm{vol} / \mathrm{vol}$ ), the cytokines examined (IL-I and TNF) produced cytotoxicity in primary neurons only at concentrations in the micromolar range. Furthermore, synergistic cytotoxicity was not evident when submaximal concentrations of IL-I and TNF were used together. IL-I was marginally more active than TNF in the induction of cytotoxicity in this assay. The discussion of this presentation focused on questions regarding the relative susceptibilities of embryonic neurons and neurons of older animals, the change of embryonic neurons with age in culture, the response of embryonic neurons to $\mathrm{N}$-methyl-D-aspartate antagonists, and other issues. Primary neurons are remarkably resistant to cytokines in this system.

\section{Leukocyte-Endothelial Cell Interactions}

The critical role of leukocyte-endothelial cell interactions in tissue injury - and potentially in bacterial meningitiswas addressed in several presentations. The broad subject of these interactions in tissue injury was reviewed by Hans-Anton Lehr (Munich). The crucial role of leukocyte-endothelial cell interactions in host defense is underscored by the development of recurrent bacterial infections in patients with leukocyte adhesion deficiency. Without the adhesion of leukocytes, there is no inflammatory response to facilitate the elimination of an invading microorganism. However, there is potentially harmful leukocyte activity. Leukocyteendothelial cell interactions may cause a local endothelial lesion, and chemotactic mediators, including leukotrienes, complement, reactive oxygen species, and platelet-activating factor, may subsequently be released from the endothelium. The liberation of these mediators leads to further recruitment of leukocytes at the site of endothelial-cell damage. Attracted activated leukocytes may release cytotoxic products, such as reactive oxygen species, reactive nitrogen intermediates, and proteolytic enzymes, that may augment tissue damage, with subsequent edema formation. This leukocyteinduced tissue damage plays a role in a variety of disease processes, such as ischemia-reperfusion [30], atherogenesis [31], and bacterial meningitis [32, 33].

Ruggero Pardi (Milan, Italy) discussed the molecular mechanisms underlying leukocyte-endothelial cell interac- tions. Aspects of adhesion, including the bidirectional mechanism of receptor density, the ability to diffuse within membranes, and ligand affinity, are the focus of Pardi's experiments. Leukocyte-endothelial cell interactions are mediated by cell-surface adhesion receptors and their counter-receptors on leukocytes and endothelial cells, which include members of the integrin and selectin families and the immunoglobulin superfamily. Pardi reviewed the interactions of leukocytic integrins (integral membrane proteins) with intercellular adhesion molecules (ICAM) and with endothelial integrins; these interactions are of low affinity in the millimolar range. Conversely, selectin-carbohydrate protein interactions are of high affinity in the nanomolar range, but the association-dissociation of these events is very rapid. $\mathrm{L}$-selectin interacts with a vascular addressin rich in carbohydrates and important in the homing of lymphocytes. Pardi suggested that leukocytes are never adhesive under resting conditions; thus leukocyte adhesiveness requires triggering by external stimuli. Increasing evidence supports the involvement of members of the selectin family (namely, L-selectin expressed by leukocytes and P-selectin on endothelial cells) in the initial rolling of leukocytes along the endothelium. This process precedes firm adhesion and transmigration [34]. The earliest detectable intracellular event associated with adhesion-membrane phosphoinositide breakdown followed by the production of inositol-1,4,5-triphosphate and diacylglycerol-results in calcium-dependent protein kinase $\mathrm{C}$ activation and a transient $\mathrm{Ca}^{2+}$ increase [34]. In Pardi's proposed model, leukocyte adhesion is dependent on activation and mediated by lymphocyte function-associated antigen 1 . The discussion of this presentation centered on potential second messengers relevant to leukocyte-endothelial cell interactions. Pardi reported that many leukocyte adhesion molecules are signal transducers. For example, after the adhesion of neutrophils, the dominant neutrophil integrin (CDIlb/ CD18) triggers the generation of oscillating intracellular calcium transients, which are associated with exocytosis and phagosome-lysosome activity.

The relevance of these complex interactions of leukocytes and endothelial cells for bacterial meningitis was the subject of the next presentation, which was delivered by Eva Rozdzinski (New York). She described a hypothetical scheme in which the entry of bacteria in to the CSF is followed by the release of cell-wall or other inflammatory stimulants whose enhancement of leukocyte adhesion to endothelial cells (with modulation by cytokines) leads to alterations in bloodbrain barrier permeability. Rozdzinski also reviewed selectin-mediated leukocyte-endothelial cell rolling mechanisms and subsequent integrin-mediated adhesion events. The influence of these two sequential mechanisms on the microcirculation of the CNS is poorly understood. Rozdzinski reviewed experiments with a monoclonal antibody to adhesion-promoting receptors on leukocytes $\left(\mathrm{IB}_{4}\right)$ in a rabbit model of meningitis [32]. Treatment of rabbits with $\mathrm{IB}_{4}(\mathrm{l}$ 
$\mathrm{mg} / \mathrm{kg}$ ) reduced CSF pleocytosis after challenge with live bacteria (meningococci, pneumococci, or Hib). pneumococcal cell wall, or Hib LPS. IB $_{4}$ did not influence the incidence of bacteremia in this model but did improve rates of survival. Evidence suggests that $\mathrm{IB}_{4}$ reduced leukocyte migration across an endothelial-cell monolayer in vitro in a dose-dependent manner. In studies of rabbits with pneumococcal meningitis, Rozdzinski and colleagues administered ampicillin 15 hours after infection and then administered $\mathrm{IB}_{4}$ and dexamethasone by the iv route. $I_{4}$ appeared to be more effective than dexamethasone in the reduction of CSF pleocytosis. Furthermore, and perhaps somewhat surprisingly, $I B_{4}$ appeared to be more effective than the combination of $\mathrm{IB}_{4}$ and dexamethasone in this model. These results conflict with data from previous studies of experimental I lib meningitis [33]. Inhibition of leukocyte-endothelial cell interactions, with the reduction of CSF pleocytosis, probably has both negative and positive consequences in the human host. This possibility must be studied carefully before relevant clinical trials are contemplated.

The $\mathrm{IB}_{4}$ study demonstrated that members of the integrin family are involved in leukocyte-endothelial cell interaction and in subsequent injury during pneumococcal meningitis. In a further study, the role of members of the selectin family in the pathophysiology of pneumococcal meningitis was studied. Selectins are $\mathrm{C}$-type lectins that recognize carbohydrates on leukocytes. These proteins are expressed on injured endothelial cells and promote leukocytc margination. Rozdzinski presented evidence suggesting that subunits $S 2$ and $S 3$ of pertussis toxin contain carbohydrate recognition domains and are thus competitive inhibitors of selectin-mediated leukocyte-endothelial cell interactions [35]. S2 and S3 peptides inhibited the adherence of human neutrophils to human umbilical-vein endothelial cells and induced upregulation of the integrin CR3 on neutrophils in vitro. Rozdzinski and her colleagues are searching for peptides that block endothelialcell adhesion without upregulation of integrins. In the animal model, the systemic administration of these peplides 1 hour after the injection of heat-killed pneumococci of strain $\mathrm{R} 6$ in to the cisterna magna reduced CSF inflammation. The potential for the use of these agents in the systemic treatment of meningitis in patients was discussed extensively after this presentation.

Confocal laser scanning microscopy, a sophisticated new technique for the imaging of leukocyte-endothelial cell interactions in vivo. was described by Stefan Lorenzl (Munich). Lorenzl and associates investigated dynamic characteristics of rhodamine $6 \mathrm{G}$-labeled leukocytes in the pial microcirculation during the first 6 hours after the induction of pneumococcal meningitis in the rat [36]. Closed cranial windows were implanted for the examination of the pial vessels in vivo. Through optical sectioning, confocal laser scanning microscopy allows the study of pial vessels through an intact dura mater. A video depicting leukocyte-endothelial

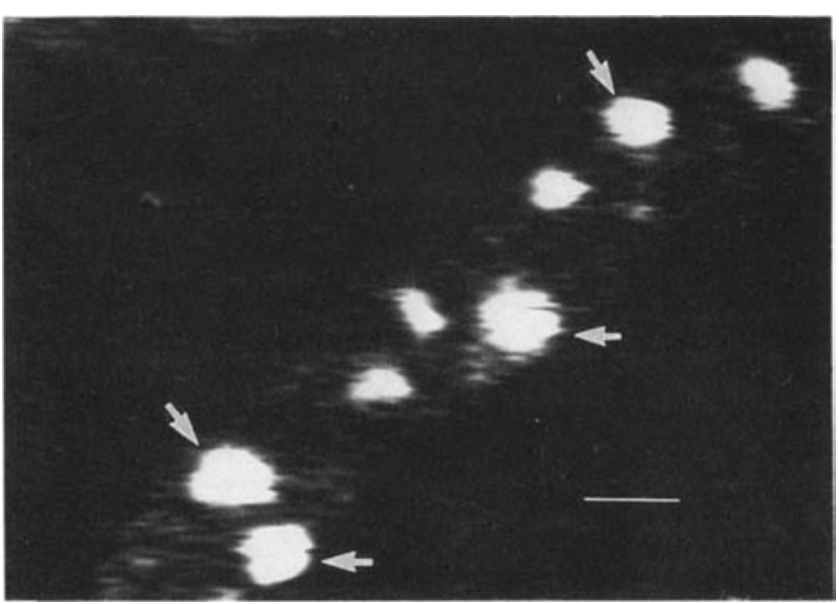

Figure 3. Leukocyte adherence to microvascular endothelium in a pial venule of an infected rat. A closed cranial window was implanted in an anesthetized rat without removal of the dura mater. and confocal laser scanning microscopy was used for in vivo examination of the cerebral microcirculation. Intravenous rhodamine $66^{\circ}$ selectively stained white blood cells and platelets but not endothelial cells. The number of rhodamine $6 \mathrm{G}$-labeled leukocytes adhering to venular endothelium was increased 3 hours after intracisternal injection of live pneumococci (arrows). Bar $=10 \mu \mathrm{m}$.

cell interactions in real time was shown: this video documented the augmented adhesion of leukocytes to the cerebral microvasculature as early as 1 hour after pneumococcal infection in the rat model. Leukocyte adherence to microvascular endothelium occurred in pial venules but not in arterioles (figure 3). Pretreatment of the rats with dexamethasonc decreased leukocyte adhesion and extravasation into the extracellular space. Administration of the novel 21 -aminosteroid agent U743891: a potent inhibitor of lipid peroxidation [37], also appeared to decrease leukocyte extravasation. The mechanism of the effect of U74389F on leukocyte-endothelial cell interactions is unknown.

\section{Molecular Mechanisms of Neuronal Injury}

A potpourri of eight presentations examined various putative mediators of neuronal injury during meningitiscurrently a primary topic of investigation. The production of nitric oxide. superoxide. and peroxynitrite by activated inflammatory cells was reviewed by Joseph Beckman (Birmingham, Alabama. USA). Reactive oxygen species have been implicated as mediators of brain injury in a variety of conditions, including cerebral ischemia/reperfusion injury. experimental fluid/percussion brain injury, cold-induced brain edema. cerebral arteriolar abnormalities after acute arterial hypertension. and bacterial meningitis $[38-40]$. Superoxide radical and hydrogen peroxide may interact via the iron-catalyzed Haber-Weiss reaction to produce the highly active hydroxyl radical, which, in turn, may initiate lipid per- 
oxidation and cellular injury. Beckman presented evidence suggesting that the Haber-Weiss reaction is too slow to damage tissue in vivo. In contrast, the interaction of superoxide with nitric oxide to form the powerful oxidant peroxynitrite anion occurs at the very high rate of $6.7 \times 10^{9} \mathrm{M}^{-1} \mathrm{~s}^{-1}$ and therefore is $\sim 1$ million times faster than the Haber-Weiss reaction. Pathological conditions such as inflammation, ischemia followed by reperfusion, and sepsis can substantially upregulate the production of superoxide and nitric oxide in stimulated macrophages and neutrophils, thereby increasing peroxynitrite formation. When protonated, peroxynitrite decomposes to generate highly reactive agents-apparently hydroxyl radical and nitrogen dioxide $\left(\mathrm{NO}_{2}\right)$ [4!]. At physiological $\mathrm{pH}$, peroxynitrite has a half-life of $\sim 1$ second that allows it to diffuse to critical cellular targets before decomposing. Thus, peroxynitrite can diffuse $\sim 10,000$ times longer than the hydroxyl radical. Peroxynitrite interacts with various metals to form nitro groups on proteins as a marker of its presence. Superoxide dismutase (SOD), which inactivates superoxide anion radical, may prevent the formation of toxic peroxynitrite from superoxide and nitric oxide [41]. However, it has been shown that peroxynitrite reacts with SOD to produce a species with the reactivity of a toxic nitronium ion $\left(\mathrm{NO}^{2+}\right)$; as a result, tissue injury is perpetuated [42]. Since catalase scavenges nitric oxide in addition to hydrogen peroxide, in vivo experiments with catalase must be interpreted with caution.

Beckman presented satisfactory evidence suggesting that peroxynitrite (as opposed to nitric oxide) is a neuronal toxin in vivo. The cytotoxic peroxynitrite has been implicated as a mediator of cerebral ischemic injury [4I]. The concentration of nitric oxide synthase is highest in the brain-i.e., at least 20-fold higher than levels in endothelial cells. Nitric oxide concentrations of 2-4 $\mu M$ in ischemic brain [43] account for $\sim 10 \%$ of oxygen consumption by the CNS during ischemia. These concentrations should be contrasted with nitric oxide concentrations within macrophages, as opposed to $0.4 \mu M$ in endothelial cells and much less than $0.1 \mu M$ in most other cell types. Nitric oxide diffuses $\sim 45 \mu \mathrm{m}$ during its in situ half-life of $\sim 1$ second. In contrast, hydroxyl radicals perfuse only about a tenth of the diameter of a protein in situ and are therefore of doubtful significance during ischemia. Beckman presented evidence suggesting that nitric oxide itself does not kill bacteria in vitro, even at $1 \mathrm{~m} M$. In contrast, all $E$. coli cells were killed within 10 seconds by exposure to peroxynitrite [44].

Nitric oxide is much more than a vasodilator. It plays important roles in the control of systemic blood pressure, respiration, digestion, penile erection, platelet aggregation, cerebral blood flow, and neuronal synaptic plasticity $[42,45]$. There is increasing evidence that nitric oxide or a secondary oxidant derived from it is also involved in the pathophysiology of bacterial meningitis (see Ködel and Berkowitz below). Clearly, the production of nitric oxide in situ and its appear- ance in CSF require additional study. Furthermore, potential interactions of nitric oxide and various cytokines may be promising areas of investigation. Nitric oxide was the "molecule of the year" in 1992 [46]; those in attendance at this presentation were left with the impression that the molecule of the year in 1994 may be peroxynitrite.

The role of reactive oxygen species, a group of potential mediators of neuronal and endothelial injury during bacterial meningitis, was reviewed by Hans-Walter Pfister (Munich), who summarized experiments in a rat model of early pneumococcal meningitis. Continuous infusion of SOD $(22,000 \mathrm{U}[\mathrm{kg} \cdot \mathrm{h}] \mathrm{iv})$ prevented the early increase in regional cerebral blood flow as well as the increase in ICP and brain water content typical of this early (6-hour) model [47]. Likewise, polyethylene glycol-conjugated SOD (PEG-SOD; $10,000 \mathrm{U} / \mathrm{kg}$ iv) was effective in preventing increases in ICP and brain water content in meningitis induced by intracisternal injection of pneumococcal cell-wall components [40]. The effect of SOD infusion was more pronounced than that of catalase infusion $(25,000 \mathrm{U} /[\mathrm{kg} \cdot \mathrm{h}] \mathrm{iv})$ in the same model [48]. Perhaps more important, SOD reduced ICP and brain water content when given as late as 3 hours after intracerebral inoculation of pneumococci. A role for oxygen radicals in the pathophysiological alterations that take place during bacterial meningitis was supported by recent studies by Berkowitz and Traystman [49]. Intravenous PEG-SOD and $P E G$-catalase prevented impairment of microvascular autoregulation in Hib meningitis in rats. SOD may act by preventing the formation of toxic peroxynitrite from superoxide anion radical and nitric oxide [41]. Pfister cited results from studies by McKnight et al. [50] documenting an increase in pial arteriolar diameter following the topical application of group B streptococci to the brain surface in rats. Treatment with iv PEG-SOD (10,000 U/kg) and PEG-catalase $(20,000$ $\mathrm{U} / \mathrm{kg}$ ) before exposure to group B streptococci prevented vasodilation; this result indirectly supports a role for reactive oxygen species. Nevertheless, as was evident from the discussion of this presentation, the exact site of oxygen radical generation during bacterial meningitis is still unknown. Furthermore, in all experiments to date, the Munich group has employed an early model of bacterial meningitis (within 6 hours of challenge), and the role of reactive oxygen species in the later stages of the disease remains poorly defined.

Some preliminary results with a new optical method for the detection of free radicals in vivo were presented by Ulrich Dirnagl (Munich). Dirnagl and colleagues used a cranial window technique in the rat with lucigenine-enhanced chemiluminescence to monitor the generation of free radicals in situ [51]. The photon count rate increased after intracisternal inoculation of live pneumococci; this effect was attenuated in the presence of SOD. The strength of the method is that it allows for continuous measurement of free-radical production in situ. Although methodological concerns must still be addressed, this method is promising and may provide 
further information on the role of reactive oxygen species in experimental infection.

Indirect evidence for a pathophysiological effect of nitric oxide during the early phase of pneumococcal meningitis was presented by Uwe Ködel (Munich). Ködel utilized the early model of experimental pneumococcal meningitis in the rat [47]. Three hours after intracisternal injection of live pneumococci, $\mathrm{N}^{\mathrm{G}}$-nitro-L-arginine (L-NA), a competitive inhibitor of $\mathrm{L}$-arginine, was given by bolus injection at a dose of 5 or $10 \mathrm{mg} / \mathrm{kg}$, with a subsequent continuous iv infusion of 5 or $10 \mathrm{mg}[\mathrm{kg} \cdot \mathrm{h}]$. Acting in a dose-dependent manner, L-NA reversed the increase in regional cerebral blood flow typical of this model. In addition, this inhibitor prevented the development of brain edema and an increase in ICP and reduced the degree of CSF pleocytosis. However, the higher dose of L-NA resulted in the death of four of five rats between the second and third hour of treatment, whereas none of the rats that were infected and then either left untreated or treated with the lower dose died. Similar increased mortality rates were reported by Cobb et al. [52], who administered $\mathrm{N}^{G}$ amino-L-arginine to awake dogs after challenge with endotoxin, and by Haberl et al. [53], who administered L-NA methyl ester to rats with experimental pneumococcal meningitis. Studies investigating the effect of L-NA in uninfected rats are warranted.

Ivor D. Berkowitz (Baltimore, Maryland, USA) described experiments suggesting that nitric oxide contributes to pial arteriolar dilation and impaired autoregulation of cerebral blood flow during experimental Hib meningitis in rats. Pial vessels were directly visualized through a closed cranial window, and Hib was topically applied to the brain surface (at a concentration of $10^{5} \mathrm{cfu} / \mathrm{mL}$ of artificial CSF). Autoregulation was assessed as the ability of pial arterioles to dilate in response to hemorraghic hypotension [54]. In infected untreated rats, the degree of pial arteriolar dilation documented was $\sim 150 \%$ (with baseline dilation assigned a value of $100 \%$ ). Pretreatment of rats with $20 \mathrm{mg}$ of L-NA methyl ester $/ \mathrm{kg}$ prevented pial arteriolar dilation 4 hours later. Autoregulation of cerebral blood flow was preserved in this model after the administration of L-NA methyl ester. The results reported are in accordance with previous studies by the Munich group [53], who reported that the administration of L-NA methyl ester attenuated the pathophysiological alterations typical of the early phase of experimental pneumococcal meningitis in the rat. However, these experiments must be interpreted cautiously since L-NA methyl ester not only is thought to be a competitive antagonist of nitric oxide synthase but also has been shown to be a muscarinic receptor antagonist [55].

H. Niels Diemer (Copenhagen, Denmark) next reviewed the role of excitatory amino acids in CNS pathology. The excitotoxic hypothesis of neuronal injury proposes that glutamate or related endogenous excitatory neurotransmitters become toxic through their interaction with glutamate recep- tors and that subsequent intracellular events result in neuronal death $[56,57]$. The glutamate receptors are divided into groups: the ionotropic $N$-methyl-D-aspartate (NMDA) receptors: the non-NMDA. kainate/quisqualate receptors: and the metabotropic glutamate receptors, which instead of possessing an intrinsic ion channel exert their effects through second-messenger systems by activation of a $(;$ protein. The protective effects of glutamate receptor antagonists suggest that excitatory amino acids are involved in the pathogenesis of cerebral ischemia, profound hypoglycemia. and status epilepticus. Elevated cxtraccllular concentrations of glutamate and aspartate in rat hippocampus during transient ischemia have been documented by microdialysis techniques [58]. Reuptake of amino acids is energy dependent at the synapse via transporters on a sodium-potassium gradient: the loss of this gradient during ischemia leads to the accumulation of these toxic amino acids. The use of NMDA antagonists, including MK-801 and $\alpha$-amino-3-hvdroxy-5-methyl-4-isoxazolepropionic acid (AMPA) antagonists such as 2,3-dihydroxy-6-nitro-7-sulfamoyl-benzo (f) quinoxaline, to protect ischemic tissues is a focus of intense investigation. The AMPA receptor is pentameric. Diemer presented evidence showing that the components of this receptor are encoded on different chromosomes: these components are designated gluR I through gluR4. A change in a single amino acid in gluR2 determines whether or not the channel is permeable to calcium. Various mechanisms that may attenuate the NMDA receptor-mediated current were discussed. For example, the accumulation of lactate in the (SF during bacterial meningtis renders the extracellular milieu acidic, and this acidity may reduce the potential for damage after meningitis and/or hypoglycemia-hypoxia. The current status of MK801 was raised during the discussion: this compound has not been introduced into clinical practice becausc of its piychomimetic properties.

The potential role of excitatory amino acids in the pathophysiology of bacterial meningitis was reviewed by Martin G. Täuber (San Francisco). Five papers, publisbed from 1975 to 1982, documented elevated concentrations of amino acids-including $\gamma$-aminobutyric acid. glutamate. glycinc, and aspartate-in (SF from patients with bacterial meningitis (cited in 159]). (oncentrations of amino acids in CSF appear to peak 1 or 2 days after initiation of therapy. No data are available on amino-acid accumulation in the brain of patients with bacterial meningitis. Täuber reviewed the results of measurements of amino acid concentrations in the CSF and brain of rabbits with pneumococcal meningitis [59]. Standard CSF analyses were conducted. and microdialysis techniques were used to document the accumulation of both lactate and amino acids in brain interstitial fluid. Concentrations of glutamate, aspartate. glycine. taurine and alanine increased after 22 hours in CSF from infected animals; there was no concomitant increase in the level of asparagine, serine, or threonine. Glutamate was the only excitatory amino 
acid to appear in increased concentrations in brain interstitial fluid after 22 hours. Levels of alanine also increased significantly at this site after 22 hours. As alanine is considered a marker for anaerobic glycolysis, perhaps it was not surprising that its concentrations in brain interstitial fluid were correlated with those of lactate. Täuber also noted an increase in levels of quinolinic acid in CSF and brain during experimental bacterial meningitis. This substance plays a potential role in the development of encephalopathy in patients with AIDS, but its role in meningitis is unknown. Much of the discussion of this presentation was concerned with the mechanism(s) of excitatory amino-acid accumulation in the brain during meningitis. Alterations in bloodbrain harrier permeability to amino acids, the release of amino acids from cells within the CNS, a decline in mechanisms of amino-acid clearance from the SAS, and accentuated binding of amino acids to brain tissue are all possibilities. These issues are difficult to study in vivo with current techniques.

Adriano Fontana (Zurich) presented intriguing information on the potential neurotoxicity of macrophages. Neurons were isolated from the cerebellum of 7-day-old mice and exposed to macrophages at a ratio of 1 macrophage to 10 neurons $[60,61]$. The neurons were destroyed within 24 hours in this in vitro system. IL-1, TNF, IL-6, and IFN- $\gamma$ - both alone and in combination-were not cytotoxic. In cocultures of macrophages and neurons, induced neurotoxicity was blocked by an NMDA receptor blocker but not by catalase or SOD. This result raised the interesting possibility that macrophages produce excitatory amino acids that contribute to neuronal toxicity. Direct evidence was provided that macrophages release glutamate, which can be detoxified by astrocytes. Thus, a balance between the amount of glutamate produced and the capacity for its detoxification by astrocytes may be crucial to the development of macrophage-mediated neurotoxicity. The contribution of excitatory amino acids to this form of toxicity requires further study.

\section{Cerebral Blood Flow and Metabolism During Bacterial Meningitis}

Jay H. Tureen (San Francisco) reviewed the changes in cerebral blood flow and metabolism in bacterial meningitis. A decrease in cerebral blood flow has been observed in patients with this infection [62-65]. The data on cerebral blood flow in animals with experimental meningitis are extensive and sometimes conflicting. As assessed by the radiolabeled microsphere technique, cerebral blood flow varies somewhat with time after experimental infection. There is an early hyperemic phase during experimental pneumococcal meningitis in the rabbit (a finding similar to those obtained by the Munich group using Doppler flow techniques in a rat model), with a decline in blood flow later in infection. Twenty hours after pneumococcal challenge, total cerebral blood flow is reduced by $\sim 25 \%$. Hippocampal blood flow in the same animal is reduced to $\sim 50 \%$ of control values. Whereas autoregulation of cerebral blood flow is maintained in normal animals, this ability is generally lost during experimental pneumococcal meningitis [66]. ICP remains stable despite marked alterations in cerebral blood flow in normal animals but rises progressively with changes in cerebral blood flow in animals infected with pneumococci. Therefore, artificial increases in blood pressure lead to increases in cerebral blood flow, which in turn lead to increases in ICP in animals with meningitis. Fluid-restricted rabbits have further decreases in mean arterial pressures and cerebral blood flow, with the accumulation of CSF lactate after treatment with ceftriaxone, whereas these changes do not occur in euvolemic rabbits [67]. The implications for the policy of fluid restriction, which may be adhered to rigidly during the early phase of meningitis because of concerns about the syndrome of inappropriate secretion of antidiuretic hormone, were not lost on the participants during the discussion period. Furthermore, cerebral blood flow declines more rapidly after antimicrobial therapy. A more rapid reduction in the bacterial titer in CSF causes a more rapid reduction in cerebral blood flow, with obvious potential implications for therapy. Tureen also reviewed microdialysis experiments whose results supported the concept that at least some CSF lactate is produced locally in the brain parenchyma [68]. Other possible sources of CSF lactate are bacteria and leukocytes. The rate of glucose extraction across the brain does not change over time, whereas the rate of cerebral oxygen metabolism falls after challenge with bacteria at high concentrations. Tureen's review raised much concern over the delicate balance among cerebral perfusion pressure, fluid restriction. ICP, and cerebral blood flow in patients with meningitis. An additional source of concern is the possibility that a rapid decrease in bacterial titer as a consequence of rapidly bactericidal therapy may temporarily decrease cerebral blood flow.

Anthony Slater (London, United Kingdom) discussed cerebrovascular autoregulation during experimental Hib meningitis in rabbits and the role of leukocytes in this interaction [69]. In contrast to results obtained with previous models [66], the rate of cerebral blood flow measured in these rabbits with the microsphere technique was increased 18 hours after intracerebral Hib challenge. Pretreatment of the animals with monoclonal antibody $\left(\mathrm{IB}_{4}, 1.5 \mathrm{mg} / \mathrm{kg}\right)$ decreased CSF pleocytosis (consistent with previous observations [32]) but was associated with an increase in bacterial concentrations in the CSF. Moreover, such pretreatment augmented cerebral hyperemia in this model, and the increase in cerebral blood flow was correlated with increased bacterial titers in CSF. Cerebrovascular autoregulation, as assessed by blood-flow measurements at graded levels of hemorrhagic hypotension, was preserved in Hib meningitis, but the capacity for autoregulation was lost in infected $\mathrm{IB}_{4}$-treated animals. The discussion of this presentation focused on prob- 
lems with Hib as a pathogen in the rabbit model: this organism does not induce a universally lethal infection in this model.

The use of transcranial Doppler (TCD) sonography in patients with bacterial meningitis was described by Hans-Peter Haring (Innsbruck. Austria). Haring and his colleagues studied 110 patients with various infections of the CNS; $37 \%$ of patients had bacterial infection, $24 \%$ had viral processes, and $39 \%$ had unclassified disease [70]. TCD sonography documented an increase of blood-flow velocity in the middle cerebral artery in $77 \%$ of patients infected with pneumococci and in $65 \%$ of those with meningococcal meningitis. Flow velocities were maximal 3-5 days into the illness and took 10-14 days to return to normal. Various causes of the observed increase in flow velocity through the $\mathrm{M} l$ segment of the middle cerebral artery, including increased cerebral blood flow. decreased vessel diameter, and decreased cerebrovascular peripheral resistance, were considered during the discussion of this presentation. The contribution of these processes to the documented result requires further study. The specificity of the observation is also unknown. The impact of treatment with dexamethasone or other adjunctive agents on the results of TCD sonography has not been studied.

\section{Approaches to the Treatment of Bacterial Meningitis}

Erich Schmutzhard (Innsbruck) reviewed the treatment of bacterial meningitis with antimicrobial agents. Schmutzhard questioned the value of heparin and raised the possibility of administering cytokine antagonists. He discussed in some depth the potential role of dexamethasone as an adjunct to antimicrobial therapy for meningitis. A meta-analysis covering data from five studies on the subject has recently been published [71]. All of the data were for cases in children and supported the contention that rates of early and late neurological sequelae-particularly severe bilateral sensorineural hearing loss-are reduced by concomitant therapy with dexamethasone. Nevertheless, only one clinical trial showed a marked effect on both parameters [4], and the incidence of neurological sequelae tended to be unusually high in the control groups in these trials. Schmutzhard suggested that further study of this issue was necessary. He also discussed the possibility that third-generation cephalosporins are not as efficacious as ampicillin and chloramphenicol in therapy for bacterial meningitis because they exacerbate the inflammatory burst. The limitations of the data on dexamethasone were considered during the discussion. The abandonment of third-generation cephalosporins as empirical therapy for meningitis in adults was not endorsed. Moreover, the recommendation for a stepwise increase in the antibiotic dose used in the treatment of pneumococcal disease did not meet with favor among the clinicians in attendance.

Terry O'Reilly (Basel) presented the results of two studies. The first described a rabbit model of LPS-induced meningitis that mimicked magnification of the inflammatory burst following antibiotic therapy. Meningitis was induced in rabbits by intracisternal inoculation of $2.5 \mathrm{ng}$ of I.PS. The resulting primary inflammation was followed 6 hours later by an injection of $25 \mathrm{ng}$ of LPS. which produced a secondary inflammation simulating the accentuation of SAS inflammation after antibiotic therapy. The administration of dexamethasone $(1.5 \mathrm{mg} / \mathrm{kg}$ iv) 15 minutes before the second injection of LPS inhibited the second peak of LPS-induced CSF inflammation. In addition. dexamethasone tended to reduce the second peak in the TNF concentration in CSF following chatlenge with LPS. Somewhat surprisingly, brain levels of TNF mRNA after 7 hours were similar in dexamethasone-treated rabbits and controls.

In another presentation. O'Reilly discussed adjunctive treatment in an experimental animal model of meningitis and reviewed the results of experiments conducted by Otto Zak and colleagues $[72,73]$. This series of studies charted mortality and neurological sequelac in a large number of rabbits in which pneumococcal meningitis was treated with ampicillin and various anti-inflammatory agents. Treatment was started 18 hours after infection. with all agents given twice daily for 3 days. The mortality in the first 30 days was clearly lowest among animals that received ampicillin (25 $\mathrm{mg} / \mathrm{kg}$ ) plus oxindanac $(5 \mathrm{mg} / \mathrm{kg}$ ), an experimental nonsteroidal anti-inflammatory drug. rather than ampicillin alone. ampicillin plus dexamethasone $(1 \mathrm{mg} / \mathrm{kg}$ ). ampicillin plus indomethacin $(5 \mathrm{mg} / \mathrm{kg})$, or no treatment. Although all antiinflammatory drugs tended to reduce rates of neurological sequelae. the results were best for ampicillin plus oxindanac The duration of ncurological sequelae was also reduced by this combination. The discussion of this presentation focused on the mechanism(s) responsible for the observed results. $\Lambda$ "weaker" nonsteroidal anti-inflammatory agent mav be more effective in this model, since indomethacin reduces concentrations of prostaglandin $\mathrm{E}_{2}\left(\mathrm{PCE}_{2}\right)$ in ( $\mathrm{SF}$ whereas oxindanac does not. A reduction in $\mathrm{PGE}_{2}$ levels may actually increase inflammation and therefore may be counterproductive.

The role of antibiotics other than $\beta$-lactam agents in therapy for pneumococcal meningitis was discussed by Martin G. Täuber (San Francisco). When a series of quinolones were evaluated in the rabbit model of experimental pneumococcal meningitis. a good correlation was found between the ratio of the peak CSI concentration to the MBC of the infecting strain and the ultimate outcome of treatment. CP116,517 and temafloxacin were more effective in the eradication of pneumococci from the CSF than was either ofloxatcin or ciprofloxacin. Somewhat surprisingly, the rate of killing in the CSF after the infusion of rifampin was only $\sim 0.25$ logs per hour-much lower than that observed with maximally active $\beta$-lactam antibiotics-despite very favorable $\mathrm{MBC}$ values for rifampin. (larithromycin was generally ineffective despite peak CSF concentration-to-MBC ratios of 
26-288. The ready entry of clarithromycin into CSF underscores the lack of activity of bacteriostatic agents in this infection. The discussion of this presentation emphasized the need for caution with the use of quinolones in the treatment of meningitis. There was a general agreement that macrolides should not be used and some enthusiasm for the testing of meropenem and other new carbapenems. Furthermore. the discussion highlighted the critical importance of testing "bactericidal" agents in vivo before using them in humans; for example, clarithromycin may be bactericidal under some circumstances in vitro but was clearly ineffective in the rabbit model. In addition, the degree of CSF inflammation after treatment with quinolones was very similar to that after treatment with $\beta$-lactams in this model of pneumococcal meningitis; this similarity called into question the concept that $\beta$-lactams induce greater bacteriolysis and a more pronounced inflammatory burst than other classes of antibiotics.

Finally, Hilmar Prange (Göttingen) discussed the appropriate use of ceftriaxone for the initial treatment of bacterial meningitis. As $7 \%$ of all cases of acute and subacute meningitis in northern Germany are due to L. monocytogenes, the empirical use of third-generation cephalosporins alone was questioned. Prange emphasized the poor CSF penetration of ceftriaxone despite CSF inflammation. Nevertheless, during the discussion, the place of third-generation cephalosporins in the empirical treatment of meningitis in adults-with the addition of ampicillin to the regimen when $L$. monocytogenes is a likely pathogen - was reaffirmed. The emergence of cephalosporin-resistant, penicillin-resistant pneumococci may dampen enthusiasm for this regimen in the future.

\section{Areas for Future Research}

The presentations at this workshop were summarized by W. Michael Scheld (Charlottesville, Virginia, USA). The following topics were suggested as areas for fruitful research and collaboration in the future.

(1) Identification and clarification of the bacterial signals responsible for pathophysiological changes in the SAS are of critical importance. Receptors within the SAS are obviously capable of recognizing minimal alterations in putative bacterial signals.

(2) The virulence factors responsible for bacterial entry, survival, and multiplication within the CNS also require further study. The genes and signals associated with the expression of these factors during the various phases of the disease process are of interest.

(3) The putative neurotropism of bacterial pathogens should be investigated further. At least three hypotheses have been formulated; these hypotheses center on the role of bacteremia and its magnitude, bacterial adhesion to CNS sites, and bacterial entry (within macrophages) into the CNS, respectively. The tools needed for relevant studies are at hand.
(4) The interaction of bacteria and/or their components with resident cells of the CNS in vitro is a fruitful area for study. Many of the experiments described at the workshop documented the interaction of bacteria with other cells, including endothelial cells, astrocytes, and primary neurons in culture. The influence of cell age, cell source, and many other variables needs further scrutiny.

(5) The role of soluble cytokines in the pathophysiology of meningitis seems certain, but the complex interplay of the various cytokines clearly requires more study. IL-8 probably plays a role and deserves further study as a synergistic cytokine. Monoclonal antibodies to IL- 8 and LPS should be studied together. The roles of IL-10 and other anticytokine or noninflammatory cytokines later in the disease are of interest. Monoclonal antibodies to TNF- $\alpha$ may profoundly influence cerebral blood flow, CSF lactate levels, and other pathophysiological parameters.

(6) The value of measurements of CSF cytokine concentrations in the diagnosis of meningitis should be explored. Data so far suggest that CSF concentrations of various cytokines, including IL-I and TNF, rise in bacterial meningitis (including partially treated bacterial meningitis) but not in viral meningitis. Studies of the significance of the presence of these cytokines in CSF from patients with fungal meningitis are under way. The usefulness of measurements of IL-10 in the discrimination of viral and bacterial meningitis (suggested by data from Zurich) should be evaluated further. A role for CSF concentrations of elastase- $\alpha-1$ proteinase inhibitor in the differential diagnosis of meningitis was suggested by one study presented at the workshop.

(7) Leukocyte-endothelial cell interactions are at the crux of inflammation. This finding is not unique to meningitis, but the molecular biology of these interactions are of critical importance to an understanding of this disease. Thus, aspects unique to the CNS should be pursued. It would be desirable to have immortalized brain endothelial cells in tissue culture as a model for study. Obviously, such a model would have to have all of the characteristics of endothelial cells in vivo-a daunting requirement. Vascular addressins unique to the CNS should be sought. The search for monoclonal antibodies to inhibit CSF pleocytosis should be broadened. $\mathrm{IB}_{4}$ is promising, but many other antibodies may be useful.

(8) The mechanisms of neuronal injury and the basic biology of CSF inflammation and neuronal dysfunction are essential elements in our understanding of the pathophysiology of meningitis. These areas are already the focus of research in several laboratories. The potential role of reactive oxygen species, nitric oxide, and peroxynitrite in the pathophysiology of meningitis was raised repeatedly during the workshop. The fundamental interactions of these substances with cytokines in meningitis (if at all relevant) have not been delineated. Reactive nitrogen species such as peroxynitrite and other nitro groups on proteins should be measured in CSF and in the CNS in situ. The role of SOD, PEG-SOD, 
and catalase in the treatment of meningitis should be assessed.

(9) MRI is the procedure of choice for documentation of the largely vascular complications of bacterial meningitis. Nuclear MR spectroscopy, which is capable of detecting metabolic abnormalities (including lactate production in situ). may be useful in furthering our understanding of anaerobic metabolism during clinical meningitis.

(10) Several problems with specific agents used in antimicrobial therapy for meningitis remain. These include the failure of third-generation cephalosporins in the treatment of gram-negative bacillary meningitis, the emergence of penicillin-resistant pneumococci, the disturbing trend toward higher MICs of third-generation cephalosporins against some of these penicillin-resistant pneumococci, and the persistently high mortality rates associated with meningitis due to many bacterial pathogens. Determination of the role of quinolones and carbapenems, among other agents, requires testing in animal models and, where appropriate, in humans.

(11) Prospective studies of adjunctive management strategies for bacterial meningitis should be conducted. These strategies involve not only steroids but also phenytoin (for prophylaxis. as studied recently in Spain). mannitol or glycerol (as assessed in recent clinical trials in Finland), and heparin (as discussed by Schmutzhard and others). Other adjunctive strategies-such as the systemic administration of monoclonal antibodies to reduce CSF pleocytosis; the use of combinations of monoclonal antibodies with dexamethasone: and treatment with scavengers of reactive oxygen species, nitric oxide, and/or peroxynitrite-should be tested in animal models. If appropriate in light of experimental results in animals, sequential and/or combination adjunctive therapies may be explored in patients. Insights in to the pathophysiology of CSF inflammation may be forthcoming from these studies. Although these strategies are clearly not the answer to the continuing problem of meningitis in developing countries and are potentially expensive, their evaluation will yield further information relevant to CNS inflammation, neurological dysfunction, and neurosciences in general.

\section{Challenges for the Future}

Several challenges for the future were formulated at the close of the workshop. (1) Increased collaboration between basic scientists and clinical researchers at multiple laboratories is essential. The valuable exchange of information at this meeting-in both formal and informal settings-should continue. (2) Increased collaboration is also needed among investigators in prospective, multicenter, international studies of new adjunctive and antimicrobial treatment modalities. (3) Given the pace of progress in this field, another meeting should be held in $\sim 3$ years. We hope that this review will stimulate research that will lead to important advances in the coming years.

\section{Acknowledgments}

The authors thank Uwe Ködel for preparation of the manuscript and Dagmar Förth and Debbie Ging for secretarial assistance.

\section{References}

1. Lebel MH. Freij BJ. Syrogiannopoulos GA. c1 al. Dexamethasone therapy for bacterial meningitis: results of two double-hlind. placebocontrolled trials. N Engl J Med 1988:319:964-71

2. Girgis NI. Farid Z, Mikhail IA, Farrag I. Sultan I. Kilpatrick MI: Dexamethasone treatment for hacterial meningiti in children and adults. Pediatr Infect Dis J 1989;8:848-51.

3. Kennedy WA. Hoyt MJ, Mcc racken Gill Jr. I he rok of corticosterond therapy in children with pneumoceceal meningitis. Am I I Dis ( hild 1991:145:1374-8.

4. Odio CM. Faingericht I. Paris M. et al. The benefictal elfects of early dexamethasone administration in infants and children with bacterial meningitis. N Engl J Med 1991: 324:1525-31

5. Sáez-Llorens X. Ramilo O. Mustafa MM. Mertsola J. Mce racken (jH Jr. Molecular pathophysiology of bacterial meningitis: current concepts and therapeutic implications. J Pediatr 1990: 116:671 84.

6. Quagliarello V. Scheld WM. Bacterial meningitis: pathogenesis, pathophysiology, and progress. N Engl J Med 1992:327:864-72.

7. Sande MA, Täuber MG, Scheld WM, MCCracken (iH Ir. Pathophysiology of bacterial meningitis: summary of the workshep. Pediatr Infect Dis J $1989 ; 8: 929-33$.

8. Durand ML, Calderwood SB. Weber DJ, et al Acute haterial meningitis in adults: a review of 493 episodes. N Engl J Med 1993:328:21-8.

9. Roos KL. Tunkel AR. Scheld WM. Acute balclerial meningitis in children and adults. In: Scheld WM. Whitley RJ. Durack DI. eds. Intections of the central nerwous system. New Yorh Raven Press. 1991:335-410.

10. Pfister H-W, Feiden W. Finhäupl K-M. Specorum of complication, during bacterial meningitis in adults: result of a prospective clinicit study. Arch Neurol 1993:50:575-81

11. Bohr V. Hansen B. Jessen O. et al. Eight hundred and veventy-five cases of bacterial meningitis. Part l of a three-part series clinical data prognosis, and the role of specialised hospital departments. I Infect 1983:7:21-30.

12. Bruyn GAW, Kremer HPH. de Marie S. Padberg (iW Hermans J. van Furth R. Clinical evaluation of pneumocucal meningitis in aduhe over a twelie-year period. Fur I Clin Micribiol Infect Din 1989:8:695-700.

13. Swartz MN Bacterial meningitis: more involved than just the meninges [editorial]. N Engl J Med 1984:311:912-4.

14. Tunkel AR. Scheld WM. Pathogenesis and pathoph wiology of bacterial meningitis. Clin Microbiol Rev 1993:6:118-36.

15. Dodge PR. Swartz. MN. Bacterial meningitic-a review of selected aspects. IL. Special neurologic problems, pustmenmeitic complicitions and clinicopathological correlations. $N$ rnel I Med 1965 . 272:954-60.

16. Cabral DA. Flodmark O. Farrell K. Speert DP. Prospcitive study of computed tomography in acute bacterial meningitis. I Pedian $1987,111: 201-5$.

17. Dodge PR, Davis H. Feigin RD. et al. Prospective evaluation ol hearing impairment as a sequela of acute bacterial meningitus. $N$ Fingl J Med 1984:31 1:869-74.

18. Täuber MG. Kennedy SL. Turten JII. Lowenstein DII. Experimentai pneumococcal meningitis causes central nervous avstem patholegy without inducing the 72-kd heat shock protein! Im I Pathol $1992 ; 141: 53-60$.

19. Friedland IR. Klugman KP. Failure of chloramphenicol therapy in penicillin-resistant pneumococal meningitis. Iancel 1992:339:405-8 
20. Garcia-Bustos J, Tomas7 A. Mechanism of pneumococcal cell wall degradation in vitro and in vivo. J Bacteriol 1989;171:114-9.

21. Garcia-Bustos J. Tomasz A. A biological price of antibiotic resistance: major changes in the peptidoglycan structure of penicillin-resistant pneumococci. Proc Natl Acad Sci USA 1990;87:5415-9.

22. Smith AL. Pathogenesis of Haemophilus influenzac type b meningitis. In: Keusch G. Wadström T. eds. Experimental bacterial and parasitic infections. New York: Elsevier, 1983:295-301.

23. Geelen $S$, Bhatta-Charyya C, Tuomanen E. Different mechanisms of attachment of Streptococcus pneumoniae to human macrophages and endothelial cells [abstract no 947]. In: Program and abstracts of the 32nd Interscience Conference on Antimicrobial Agents and Chemotherapy. Washington, DC: American Society for Microbiology. 1992.

24. Lassmann H, Zimprich F, Rössler K, Vass K. Inflammation in the nervous system: basic mechanisms and immunological concepts. Rev Neurol (Paris) 1991; 147:763-81.

25. Schmicd M. Breitschopf H, Gold R, et al. Apoptosis of T lymphocytes in experimental autoimmune encephalomyclitis. Evidence for programmed cell death as a mechanism to control inflammation in the brain. Am J Pathol 1993; 143:446-52.

26. Baggiolini M. Dewald B. Moser B. Interleukin-8 and related chemotactic cytokines- $\mathrm{CXC}$ and $\mathrm{CC}$ chemokines. Adv Immunol 1994; 55:97-179.

27. Moser B. Dewald B, Barella L, Schumacher C. Baggiolini M, Clark-Lewis I. Interleukin- 8 antagonists generated by $\mathrm{N}$-terminal modification. J Biol Chem 1993;268:7125-8.

28. Frei K. Nadal D, Pfister H-W, Fontana A. Listeria meningitis: identification of a cerebrospinal fluid inhibitor of macrophage listericidal function as interleukin 10. J Exp Med 1993; 178:1255-61.

29. Täuber MG. Sachdeva M. Kennedy SL. Loetscher H. Lesslauer W. Toxicity in neuronal cells caused by cerebrospinal fluid from pneumococal and gram-negative meningitis. J Infect Dis 1992; 166:1045-50.

30. Lehr HA, Guhlmann A, Nolte D. Keppler D. Messmer K. Leukotrienes as mediators in ischemia-reperfusion injury in a microcirculation model in the hamster. J Clin Invest 1991;87:2036-41.

31. Lehr HA, Hübner C. Finckh B, et al. Role of leukotrienes in leukocyte adhesion following systemic administration of oxidatively modified human low density lipoprotein in hamsters. J Clin Invest 1991:88:9-14.

32. Tuomanen EI, Saukkonen K. Sande S. Cioffe C. Wright SD. Reduction of inflammation, tissue damage, and mortality in bacterial meningitis in rabbits treated with monoclonal antibodies against adhesion-promoting receptors of leukocytes. J Exp Med 1989; 170:959-69.

33. Sáez-Llorens X, Jafari HS, Severien C, et al. Enhanced attenuation of meningeal inflammation and brain edema by concomitant administration of anti-CD18 monoclonal antibodies and dexamethasone in experimental Haemophilus meningitis. J Clin Invest 1991:88: 2003-11.

34. Pardi R. Inverardi L. Bender JR. Regulatory mechanisms in leukocyte adhesion: flexible receptors for sophisticated travelers. Immunol Today 1992; 13:224-30.

35. Rozdzinski E, Burnette WN, Jones T, Mar V. Tuomanen E. Prokaryotic peptides that block leukocyte adherence to selectins. J Exp Med 1993; 178:917-24.

36. Lorenzl S. Koedel U, Dirnagl U. Ruckdeschel G. Pfister HW. Imaging of leukocyte-endothelium interaction using in vivo confocal laser scanning microscopy during the early phase of experimental pneumococcal meningitis. J Infect Dis 1993; 168:927-33.

37. Chumas PD. Del Bigio MR, Drake JM, Tuor UI. A comparison of the protective effect of dexamethasone to other potential prophylactic agents in a neonatal rat model of cerebral hypoxia-ischemia. J Neurosurg 1993:79:414-20.
38. Kontos HA. Oxygen radicals in experimental brain injury. Intracranial Pressure VII. New York: Springer-Verlag, 1989:787-98.

39. Traystman RJ, Kirsch JR, Koehler RC. Oxygen radical mechanisms of brain injury following ischemia and reperfusion. J Appl Physiol 1991:71:1185-95.

40. Pfister H-W, Koedel U, Lorenzl S, Tomasz A. Antioxidants attenuate microvascular changes in the early phase of experimental pneumococcal meningitis in rats. Stroke 1992;23:1798-804.

41. Beckman JS, Beckman TW, Chen J. Marshall PA, Frecman BA. Apparent hydroxyl radical production by peroxynitrite: implications for endothelial injury from nitric oxide and superoxide. Proc Natl Acad Sci USA 1990;87:1620-4.

42. Beckman JS. Crow JP. Pathological implications of nitric oxide, superoxide and peroxynitritc formation. Biochem Soc Trans 1993; $21: 330-4$.

43. Malinski T, Bailey F, Zhang ZG, Chopp M. Nitric oxide measured by a porphyrinic microsensor in rat brain after transient middle cerebral artery occlusion. J Cereb Blood Flow Metab 1993; 13:355-8.

44. Zhu L, Gunn C, Beckman JS. Bactericidal activity of peroxynitrite, Arch Biochem Biophys 1992;298:452-7.

45. Moncada S, Palmer RMJ, Higgs EA. Nitric oxide: physiology, pathophysiology and pharmacology. Pharmacol Rev 1991:43:109-42.

46. Koshland DE Jr. The molecule of the year [editorial]. Science 1992;258:1861.

47. Pfister H-W, Koedel U, Haberl RL, et al. Microvascular changes during the early phase of experimental bacterial meningitis. J Cereb Blood Flow Metab 1990; 10:914-22.

48. Pfister H-W, Ködel U, Dirnagl U, Haberl RL, Ruckdeschel G, Einhäupl KM. Effect of catalase on regional cerebral blood flow and brain edema during the early phase of experimental pneumococcal meningitis. J lnfect Dis 1992;166:1442-5.

49. Berkowitz ID, Traystman RJ. Oxygen radical scavengers prevent impairment of microvascular autoregulation in $\mathrm{H}$. influenzale type $B$ meningitis in rats [abstract no 3077]. FASEB J 1993; 7(4):A530.

50. McKnight AA, Keyes WG. Hudak ML, Jones MD Jr. Oxygen free radicals and the cerebral arteriolar response to group $B$ streptococci. Pediatr Res 1992;31:640-4.

51. Dirnagl U. Ködel U, Pfister HW, Villringer A. Schleinkofer L, Einhäupl KM. Detection of brain free oxygen radical generated photons in vivo: preliminary results. Adv Exp Med Biol 1993;333: $203-12$

52. Cobb JP, Natanson C. Ilofman WD. et al. Nw-amino-L-arginine, an inhibitor of nitric oxide synthase, raises vascular resistance but increases mortality rates in awake canines challenged with endotoxin. $J$ Exp Med 1992; 176:1175-82.

53. Haberl RL, Anneser F, Koedel U. Pister HW. The role of L-arginine in mediating brain hemodynamic changes in experimental pneumococcal meningitis. J Vasc Res 1992;29:127.

54. Berkowitz ID. Hayden WR, Traystman RJ. Jones MD Jr. Haemophilus influenzae type B impairment of pial vessel autoregulation in rats. Pediatr Res 1993;33:48-51.

55. Buxton ILO, Cheek DJ, Eckman D, Westfall DP, Sanders KM, Keef KD. $\mathrm{N}^{\mathrm{G}}$-nitro $\mathrm{L}$-arginine methyl ester and other alkyl esters of arginine are muscarinic receptor antagonists. Circ Res 1993: 72:387-95.

56. Choi DW. Excitotoxic cell death. J Neurobiol 1992;23:1261-76.

57. Tasker RC. Excitatory amino acid neurotoxicity-a broader horizon for cerebral protection? Arch Dis Child 1992;67:1327-9.

58. Benveniste H, Drejer J, Schousboe A, Diemer NH. Elcvation of the extracellular concentrations of glutamate and aspartate in rat hippocampus during transient cerebral ischemia monitored by intracerebral microdialysis. J Neurochem 1984;43:1369-74.

59. Guerra-Romero L, Tureen JH. Fournier MA, Makrides V. Täuber MG. Amino acids in cerebrospinal and brain interstitial fluid in experimental pneumococcal meningitis. Pediatr Res 1993;33:510-3.

60. Piani D. Frei K. Do KQ. Cuénod M, Fontana A. Murine brain macro- 
phages induce NMDA receptor mediated neurotoxicily in vitro by secreting glutamate. Neurosci Lett 1991;133:159-62.

61. Piani D. Spranger M. Frei K. Schaffner A. Fontana A. Macrophage-induced cytotoxicity of $\mathrm{N}$-methyl-D-aspartate receptor positive neurons involves excitatory amino acids rather than reactive oxygen intermediates and cytokines. Eur J Immunol 1992;22:2429-36.

62. Paulson OB, Brodersen P. Hansen EL. Kristensen HS. Regional cerebral blood flow, cerebral metabolic rate of oxygen. and cerebrospinal fluid acid-base variables in patients with acute meningitis and with acute encephalitis. Acta Med Scand 1974;196:191-8.

63. McMenamin JB, Volpe JJ. Bacterial meningitis in infancy: effects on intracranial pressure and cerebral blood flow velocity. Neurology $1984 ; 34: 500-4$.

64. Aslıwal S. Stringer W. Tomasi L. Schneider S. Thompson J, Perkin R. Cerebral blood flow and carbon dioxide reactivity in children with bacterial meningitis. J Pediatr 1990: 117:523-30.

65. Förderreuther S. Tatsch K. Einhäupl KM. Pfister H-W. Abnormalities of cerebral blood flow in the acute phase of bacterial meningitis in adults. J Neurol 1992;239:431-6.

66. Tureen JH. Dworkin RJ, Kennedy SL. Sachdeva M. Sande MA. Loss of cerebrovascular autoregulation in experimental meningitis in rabbits. J Clin Invest 1990;85:577-81.

67. Tureen JH. Täuber MG. Sande MA. Effect of hydration status on cerebral blood flow and cerebrospinal fuid lactic acidosis in rabbits with experimental meningitis. J Clin lnvest 1992;89:947-53.
68. Guerra-Romero L, Täuber MG. Fournier MA. Tureen JH. Lactate and glucose concentrations in brain interstitial fluid, cerebrospinal fluid. and serum during experimental pneumococcal meningitis. I Infect Dis 1992: 166:546-50.

69. Slater AJ, Berkowic ID. Wilson DA. Traystman RJ (erebral hyperemia in Hemophilus influen\%ac type $B$ (Hib) meningitis in rabbits is not prevented by pretreatment with IB4. a monoclonal leukocyte adherence receptor antibody [abstract]. (rit (are Med 1993:2I (4)(suppl):S159.

70. Haring H-P. Rötzer H-K. Reindl H. et al. Time course of cerebral blosd flow velocity in central nervous system infections: a transcranial Doppler sonography study. Arch Neurol 1993:50:98-101.

71. Geiman BJ. Smith AL. Dexamethasone and bacterial meningitis: a mela-analysis of randomized controlled trials Wost I Mcal 1992: 157:27-31.

72. Kadurugamuwa JL. Hengstler B. Zak O. Cerebrospinal fluid protein profile in experimental pneumecoccal meningitis and its alteration by ampicillin and anti-inflammatory agents. I Infece Dis 1989 . $159: 26-34$.

73. Salamin PA. Hengstler B. O'Reilly T. Kadurugamuwa IL. Zak O. Influence of adjunct antiinflammatory agent therapy on sequelate in rabbits with experimental pneumococal meningitis [abstract no 9233. In: Program and abstracts of the 31 st Interscience conference on Antimicrobial Agents and Chemotherapy. Washington. I): American Society for Microbiology. 1991:253. 